\title{
Catatonia: diagnostic approaches and therapeutic management
}
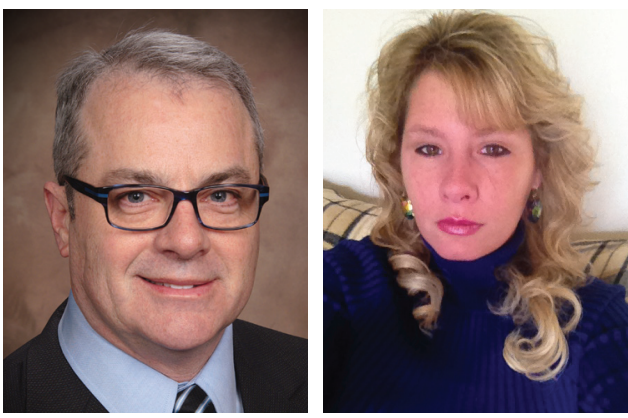

"We hope that all readers will benefit from

this comprehensive issue on catatonia, an

important yet underecognized and

undertreated syndrome."

\section{Brendan T Carroll ${ }^{*, 1} \&$ Vonny Pinson}

In the past 200 years, there has been a concerted effort by dedicated clinicians to increase the recognition, diagnosis and treatment of catatonia. There is now international, external validation of their efforts with the publication of DSM-5 and ICD-10 [1,2]. In DSM-5 catatonia was unlinked from schizophrenia [1].

Thus, catatonia is recognized as the presentation of mood, psychotic and developmental disorders. These three independent diagnostic subcategories of catatonia recognized the need to identify, diagnose and treat these primary neuropsychiatric syndromes. This modern nosology is also supported by treatment of catatonia. The diagnosis of catatonia in DSM- 5 and ICD-10 directs the clinician to tap into the unique treatment approaches described in this special issue of Future Neurology. The clinician can also identify catatonia as a risk factor for neuroleptic malignant syndrome, and to initiate clinical management to prevent the complications of catatonia.

This issue of Future Neurology goes into great detail to aid the clinician in the identification of catatonia, determining etiology and selecting treatment, and incorporates the clinical advances of the last decade [3,4]. Certainly, this issue will be of interest to researchers, students, nurses, pharmacists and physicians who have interest in psychotic disorders and neuropsychiatry. This is because they have, and will encounter, patients with catatonia in most mental health settings (especially for inpatient settings, consultation-liaison settings, neurodevelopmental clinics and emergency settings) and in most neurology settings.

There are articles on themes of nosology, classification, etiology and treatment. Each article offers either new development in the diagnosis of catatonia or in the treatment of catatonia. We hope that all readers will benefit from this comprehensive issue on catatonia, an important yet underecognized and undertreated syndrome [4].

\section{Financial \& competing interests disclosure}

The authors have no relevant affliations or financial involvement with any organization or entity with a financial interest in or financial conflict with the subject matter or materials discussed in the manuscript. This includes employment, consultancies, honoraria, stock ownership or options, expert testimony, grants or patents received or pending, or royalties.

No writing assistance was utilized in the production of this manuscript.

KEYWORDS:

- catatonia • etiology

${ }^{1} 1345$ N Fountain Blvd, Springfield, OH 45504, USA

*Author for correspondence: btcarroll1@cs.com 
FOREWORD Carroll \& Pinson

\section{References}

1 American Psychiatric Association. Diagnostic and Statistical Manual of Mental Disorders (5th Edition). Washington, DC, USA (2013).

2 World Health Organization. The ICD-10 Classification of Mental and Behavioural Disorders: Clinical Descriptions and Diagnostic Guidelines. World Health Organization. Geneva (1992).
3 Caroff SN, Mann SC, Francis A, Fricchione GL. Catatonia: From Psychopathology to Neurobiology. American Psychiatric Press (2004).

4 Fink M. Rediscovering catatonia: the biography of a treatable syndrome. Acta Psychiatr. Scand. 127(Suppl. 441), 1-50, (2013). 